\title{
Selective coupling as institutional response to sustainability development in electric utilities
}

\author{
Johannes Slacik*, Dorothea Greiling \\ Institute of Management Accounting, Johannes Kepler University Linz, Linz, Austria
}

\begin{abstract}
Electric utilities are in an environmental sensitive industry, exploiting natural resources and contributing to climate change issues. The focus of critical stakeholders on sustainability agendas and management approaches and the increasing tight sector-regulations pressure electric utilities to act and distribute sustainability reports declaring their sustainability performances and goals towards achieving climate targets. However, literature criticizes the utility's reporting practices as form of impression management being decoupled from actual sustainability compliance. This paper analyzes in light of institutional theory the compliance with or decoupling from sustainability agendas in the underresearched electricity sector by identifying the coverage of materiality in sustainability reports and the implemented sustainability management control systems for sustainability development. Quantitative and qualitative methods are used including correlation- and variance analysis of material indicators and expert interviews. This study contributes by having identified a sectorwide continuous form of selective coupling from the sustainability agendas in electric utilities. Furthermore, this paper found that sustainability agendas and the implementation of sustainability control mechanisms are governed by institutional hybrid logics which are still at an early stage.
\end{abstract}

\section{Introduction}

Climate change issues, exploitation of resources and growing environmental strain increased stakeholder pressure for companies to address and disclose not only economic but also environmental and social sustainability issues $[1,2,3,4]$ They need to find solutions to comply with the ambitious climate targets following the 2015 Paris Agreement and the United Nation Sustainability Development Goals [5, 6]. In that sense, Sustainability Development (SD) is slowly becoming a reaction and an institutionalized practice to gain, maintain or regain legitimacy and reputation [7].

Electric Utility Companies (EUC) are in a very sensitive sector being responsible for $25 \%$ of the carbon-emissions worldwide leading to social and ecological negative effects [8]. They are confronted with economic challenges, investment pressures for adopting renewable energy and carbon-neutral technologies for achieving climate targets and increasing economic and environmental regulations while securing electricity supply and financial

\footnotetext{
*Corresponding author: johannes.slacik@jku.at
} 
sustainability $[9,10]$. They represent an industry with extensive sustainability issues and stakeholder monitoring [9].

Yet the electricity sector remains under-researched regarding its SD, the implementation of Sustainability Management Control Systems (SMCS) as strategic and operative control mechanism for setting and achieving sustainability objectives including the sustainability reporting practice as an instrument of stakeholder accountability to improve public reputation $[4,9]$. In 2013, the GRI-G4-Guidelines (most dominant standard for sustainability reporting worldwide) put the disclosure of stakeholder material aspects [45], called "materiality", in the center of Sustainability Reports (SR) expecting shorter, more focused reports with relevant information. EUC can describe their strategic and operative SD in SR based on defined standardized indicators providing transparent information to their stakeholders. Literature has continuously criticized the credibility and reliability of SR for being nontransparent and a green-washing attempt implying impression management as response for enhancing a company's image $[11,12,13,49]$. Increased skepticism and criticism among stakeholders also add to the negative reputation of EUC regarding their SD [14]. Thus, SD in EUC must be guided by a fully integrated Sustainability Management (SM) and a set of control mechanisms to comply with institutional and regulatory challenges $[3,15,16,17$, 18]. How EUC manage and control their sustainability agendas for achieving climate targets is however still in question.

For strategically planning and implementing SD, [18] address the need to apply a control system. [24] claimed, that "(...) because management control systems shape actors' practices, and support strategy, they can, if used appropriately, push organization in the direction of sustainability." Literature shows that SMCS support sustainability strategy and influence organizational behavior [19, 20] thus encourage SD [15, 3, 21]. However, lack of resources and time for SM are forces for resistance while lack of knowledge and experience are reasons that hinder SM [26]. Instruments of SMCS are the sustainability balanced scorecard $[22,18]$ as well as environmental-MCS for improved sustainability performance $[23,24]$. However, how companies integrate SM and implement SMCS is still scarcely researched, only conceptional and without a sector focus $[15,16,22,25]$. This study will use 'MCS as a package' by [32] as framework for analyzing SMCS in EUC and identifying formal and informal control mechanisms for active SD and patterns for managerial behavior and boundaries.

For identifying strategic responses of EUC to regulatory and stakeholder pressures, institutional theory serves as theoretical lens [27, 34]. While isomorphism shows the institutional forces that drive companies to homogenization [28] it also assists in discovering decoupling processes [29] or a selective coupling [30]. Decoupling is noticed when EUC symbolically confirm to a structure, like disclosing a SR, while acting differently by providing insufficient information in SR. The analyses of how EUC comply with stakeholder information needs as well as the implementation of SMCS for SD show the sector-wide strategic response of EUC to compliance demands. However, the implementation of SMCS for SD is also governed by Institutional Logics (IL) which lead managerial behavior and attitudes for sustainability agendas towards compliance or else [31] show implications for decoupling [34, 51, 27, 30].

Based on prior literature reviews regarding SR and SMCS for SD in the electricity sector and the identified research gaps, this study analyzes the coverage of materiality in SR based on the GRI-G4-Guidelines to better understand the reporting practice and the response of EUC sector-wide to multiple stakeholders demands. The extent of compliance or decoupling with stakeholder information needs is still questionable providing relevance for this study. Secondly, this study investigates on implemented SMCS in EUC. While literature has already identified institutional drivers for SD, it would also be interesting to understand the 
logics that govern SD and the implementation of SMCS. Based on the research objectives, the following Research Questions (RQ) are addressed:

- RQ1: How is the coverage of materiality in G4-SR by EUC?

- $\quad R Q 2:$ Which SMCS are implemented for SD in EUC and how are these implemented?

\section{Theoretical approach}

Institutional theory helps for identifying institutional pressures that lead to sectoral homogenization [28, 29], e.g., the publishing of SR in EUC. The theoretical lens explains isomorphic forces (coercive, mimetic and normative) [28] that have the potential to influence SD in EUC. Coercive isomorphism is driven by regulators and stakeholder demands; mimetic forces are seen, when EUC imitate behavior of other legitimized and successful EUC; normative forces are driven by standard-setters, universities that provide norms for organizational behavior [33,9]. These isomorphic forces bring either forth strategic responses of total compliance, forms of decoupling or else complete avoidance [34, 27]. Furthermore, [30] have identified the response of selective coupling particularly for compliance with selective topics only. For complying with SD, [34] outlined organizational motives such as sector-specific regulations, growing scrutiny by NGOs, improving competitive advantages and complying with multiple stakeholder expectations [35]. However, literature argues, that decoupling as form of impression management is a dominant form of strategic response [34, 12].

Institutional Logics (IL) are yet another approach of institutional theory. IL are based on relations, e.g., with institutions, sector-regulators, standard-setters, investors, customers [36] that become institutional systems governing managerial behaviors, beliefs, values and attitudes, thus, influencing strategic and operative organizational patterns [37, 38, 39]. Hence, IL also guide patterns of strategic responses like compliance with or decoupling from sustainability agendas $[27,31]$. Concerning the research objectives, a deeper understanding of managerial behaviour when implementing SMCS for SD in EUC is facilitated by getting to know the governing IL that may foster, inhibit or delay SD in EUC, e.g., competing IL.

Public utilities, like the EUC used in this sample, are foremost governed by three competing IL [40] - the business logic, compliance logic and community logic - and argue how these governing logics compete with each other due to the different players (political, managerial, social) at stake, following [27]. However, [41] suggests a hybridization of public utilities for keeping a competitive advantage ensuring organizational survival, thus, being governed by hybrid logics. Management has to build new frames to integrate previously competing logics as hybrid logic especially in a sustainability context. Hence, the lack of integrating hybrid logics shows implications for decoupling [34, 51, 30]. To cope with conflicting ideals, a hybridization of logics is a managerial solution for reaching balance and organizational compromises [42]. Another coping strategy is selective coupling based on [30], hence, the implementation of selective SMCS which organizations belief help legitimize their SD.

The framework 'MCS as a package' by [32] (see Figure 1) is used to identify the various sustainability control mechanisms allied in EUC for their SD. Cultural controls reflect governing IL to existing institutional pressures that influence the culture of EUC, their beliefs and boundaries. Planning controls regard any aspect of SD including action planning on an operational level. Cybernetic controls are based on clear Key Performance Indicators (KPIs) for sustainability targets and financial and non-financial sustainability performance in EUC (e.g., carbon-emissions). Reward and compensation controls target incentives for SD and improved performances. Administrative controls target organizational and procedural boundaries, policies, communication and corporate governance structures in EUC. Focusing 
on sustainability agendas, these MCS allow for analyzing the implementation of SMCS and managerial behavior for SD in EUC [15].

\begin{tabular}{|c|c|c|c|c|c|c|}
\hline \multicolumn{7}{|c|}{ Cultural Controls } \\
\hline \multicolumn{3}{|c|}{ Clans } & \multicolumn{2}{|c|}{ Values } & \multicolumn{2}{|c|}{ Symbols } \\
\hline \multicolumn{2}{|c|}{ Planning } & \multicolumn{4}{|c|}{ Cybernetic Controls } & \multirow[b]{2}{*}{$\begin{array}{c}\text { Reward and } \\
\text { Compensation }\end{array}$} \\
\hline $\begin{array}{l}\text { Long } \\
\text { range } \\
\text { planning }\end{array}$ & $\begin{array}{c}\text { Action } \\
\text { planning }\end{array}$ & Budgets & $\begin{array}{c}\text { Financial } \\
\text { Measurement } \\
\text { Systems }\end{array}$ & $\begin{array}{l}\text { Non Financial } \\
\text { Measurement } \\
\text { Systems }\end{array}$ & $\begin{array}{c}\text { Hybrid } \\
\text { Measurement } \\
\text { Systems }\end{array}$ & \\
\hline \multicolumn{7}{|c|}{ Administrative Controls } \\
\hline \multicolumn{3}{|c|}{ Governance Structure } & \multicolumn{2}{|c|}{ Organisation Structure } & \multicolumn{2}{|c|}{ Policies and Procedures } \\
\hline
\end{tabular}

Fig. 1. MCS as a package by [32].

\section{Methodology}

This paper uses quantitative and qualitative content analysis coupled with a correlation- and variance analysis for identifying the coverage of materiality in SR and additional qualitative expert interviews for analyzing SMCS in EUC. Applied research methods are as follows:

Coverage of materiality in SR by EUC (RQ1)

186 SR worldwide (retrieved from the GRI-database and the GRI-G4 content-index in each SR) were analyzed with a content analysis (deductive category-system) identifying the (Total) Coverage Rates $((\mathrm{T}) \mathrm{CR})$. All disclosed general standard, specific and sector-specific indicators in SR including performance indicators (PI), material aspects and disclosures on management approach (DMA) were analyzed. The category-system consists of seven subcategories adding up to 222 indicators divided in economic, environmental and social indicators. A binary coding-scale was used to assess the Coverage Rate (CR): 1/0 reported/not reported. The TCR for all seven subcategories were then analyzed by dividing the number of reported indicators by the number of total indicators of each subcategory.

Additionally, $\quad \mathrm{TCR}=\frac{\sum \text { Amount of disclosed indicators }}{222 .}$ based on the TCR as dependency variable, possible determinants influencing SR like ownership (in private or in public hands ( $>50 \%$ of shares) and stock-exchange listing were coded $(0 / 1 ; \alpha=0.05)$ and analyzed.

Moreover, a qualitative content analysis based on the $186 \mathrm{SR}$ was carried out to analyze material aspects in SR. GRI recommends documenting the material aspects in materialitymatrices, which includes a classification of the stakeholder-relevance levels. Each matrix shows three levels of relevance $(1=$ low relevance, $2=$ medium relevance, $3=$ high relevance) for internal and external stakeholders. SR without a materiality matrix were excluded. Material aspects of internal and external stakeholders in each SR were identified and deductively categorized [43]. Additional material categories were complemented by means of induction.

The TCR was then calculated for each material category, e.g., if EUC No.1 reports 3 out of these 6 material indicators, the compliance level is 50\%. The compliance levels were divided into four categories for coding $(0=$ no coverage, $1=$ low coverage, $2=$ medium coverage, $3=$ high coverage). The compliance levels are: no coverage $=0,>0 \%$ to $<=$ $33.33 \%=1,>33.33 \%$ to $<=66.66 \%=2$ and $>66.66 \%=3$. If the relevance level for a material aspect is medium and the coverage of indicators is between $33.33 \%$ and $66.66 \%$ the 
information needs of stakeholders are met. Following this, a correlation analysis was performed to measure the correlation $(\alpha=0.05)$ between the documented stakeholderrelevance levels and the TCR of material aspects. The reporting of material aspects is either aligned with the relevance level or not, identifying a compliance or decoupling.

SMCS in EUC (RQ2)

In addition, qualitative interviews were conducted analyzing twelve problem-centered expert interviews (between November 2019 and January 2020) in seven public and stockexchange listed Austrian EUC (see appendix 1 for sector-details). The Austrian electricity sector is tightly regulated and predominantly state-owned with an interrelated ownership mix between each of the EUC. Experts included CEOs, sustainability representatives, internal auditors and department heads. Additional explication such as archived documents and reports to gain organizational insights were analyzed making managerial implication comparable and reasonably generalizable [44].

Finally, a qualitative content analysis of transcribed material based on the deductive (MCS) and inductive (SMCS) category formation [43] was performed. Collected information was filtered along a codification guideline of the theoretical framework (see appendix 2) to identify implemented SMCS and managerial implications.

\section{Findings}

\subsection{Coverage of indicators and materiality in SR by EUC (RQ1)}

186 GRI-G4 SR by EUC worldwide were analyzed. Results show that a bit less than $78 \%$ of all SR by EUC cover sector-specific indicators, however, on average only to $42.6 \%$. Only 30 of 186 EUC cover more than $75 \%$ in SR. $60 \%$ are SR from public EUC and $68.8 \%$ are SR from stock-exchange listed EUC.

The worldwide CR in SR in the seven subcategories and the three dimensions of sustainability are: general standard disclosures almost 75\%; all other categories cover less than $50 \%$ except labor practice and decent work. Subcategories human rights and product responsibility show the lowest $\mathrm{CR}$. A comparison of CR shows that there is a selective coverage within the subcategories (see Figure 2). None of the three dimensions of sustainability are covered beyond $48.7 \%$.

Results of influencing dependency factors of SR in relation to ownership show that 74 EUC worldwide are privately owned showing $56.5 \%$ of CR on average, while 112 public EUC worldwide cover only $49.8 \%$ with a significance of $\mathrm{p}=0.022$. The TCR of stock listed EUC $(54.9 \%)$ is slightly higher than the TCR of not-listed EUC $(47.2 \%)(p=0.021)$. The 59 private and stock listed EUC show a significant higher TCR $(\mathrm{p}=0.017)$ while 69 public and not-listed EUC show a significant lower TCR $(p=0.011)$. 

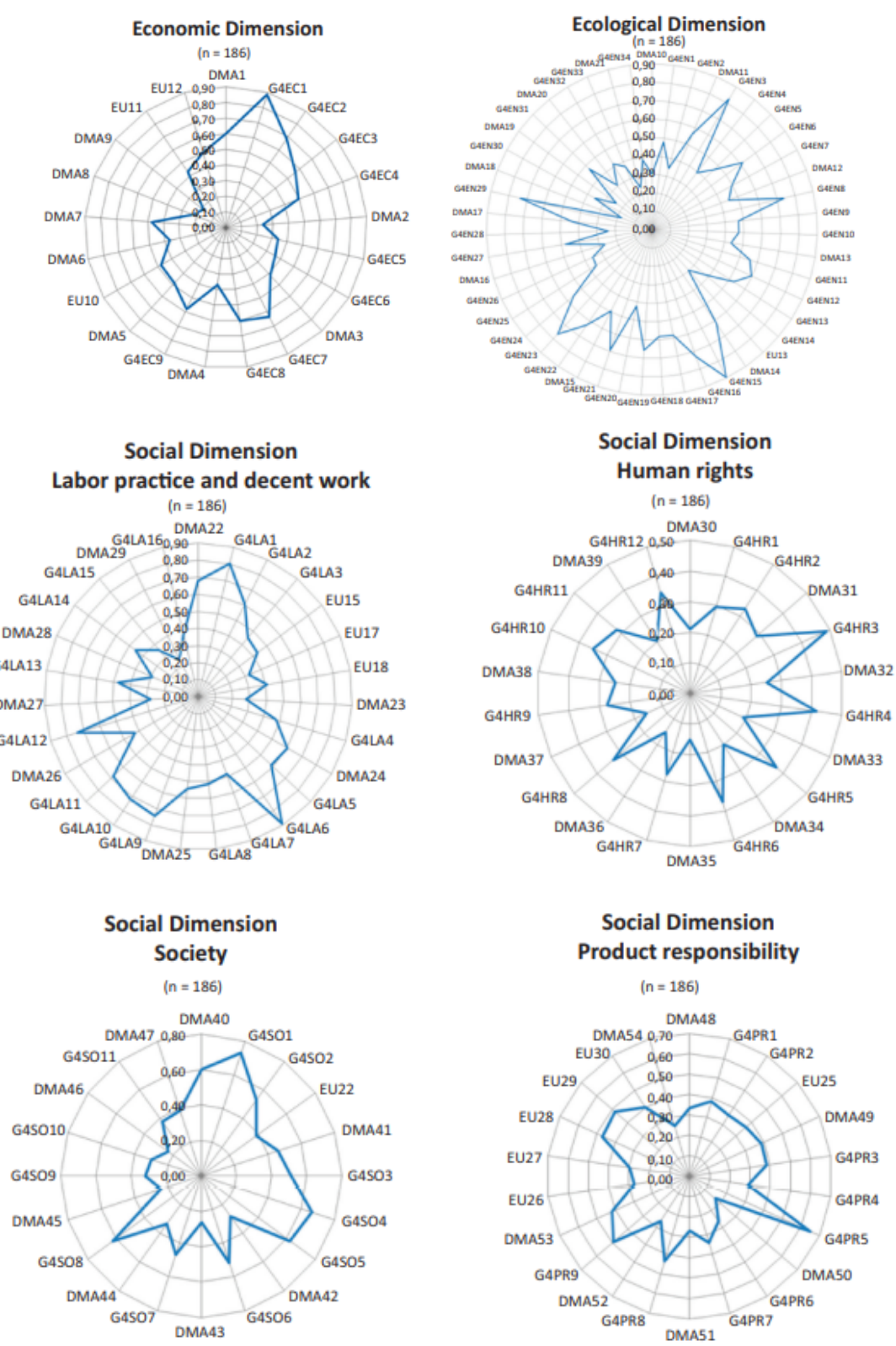

\begin{tabular}{|l|l|l|l|}
\hline Subcategories & CR Global & CR DMA & CR PI \\
\hline General Standard Disclosures & $74.6 \%$ & - & - \\
\hline Economic Disclosures & $47.0 \%$ & $37.3 \%$ & $54.6 \%$ \\
\hline Ecologic Disclosures & $48.7 \%$ & $37.7 \%$ & $52.4 \%$ \\
\hline Labor Practice and Decent Work & $50.9 \%$ & $41.7 \%$ & $55.3 \%$ \\
\hline Human Rights & $28.2 \%$ & $20.4 \%$ & $34.7 \%$ \\
\hline Society & $44.2 \%$ & $35.0 \%$ & $50.4 \%$ \\
\hline Product Responsibility & $36.3 \%$ & $30.0 \%$ & $39.2 \%$ \\
\hline
\end{tabular}

Fig. 2. Coverage of categorized G4-indicators in SR by EUC [45]. 


\subsection{Materiality}

Results show that only 58\% (108/186) of SR have a materiality matrix. The stakeholdermateriality analysis identified 22 deductive material categories and three new inductive categories: technology and innovation, risk management and investor relations. The aggregated average level of relevance for internal and external stakeholders shows 11 low relevant material categories including 'disclosure of management approach'; eight categories of medium relevance including 'Electric Utilities operational performance' or 'compliance'. Six categories from the social and environmental dimension perform particularly high, i.e. 'labour and decent work', 'society' or 'emission and climate change'.

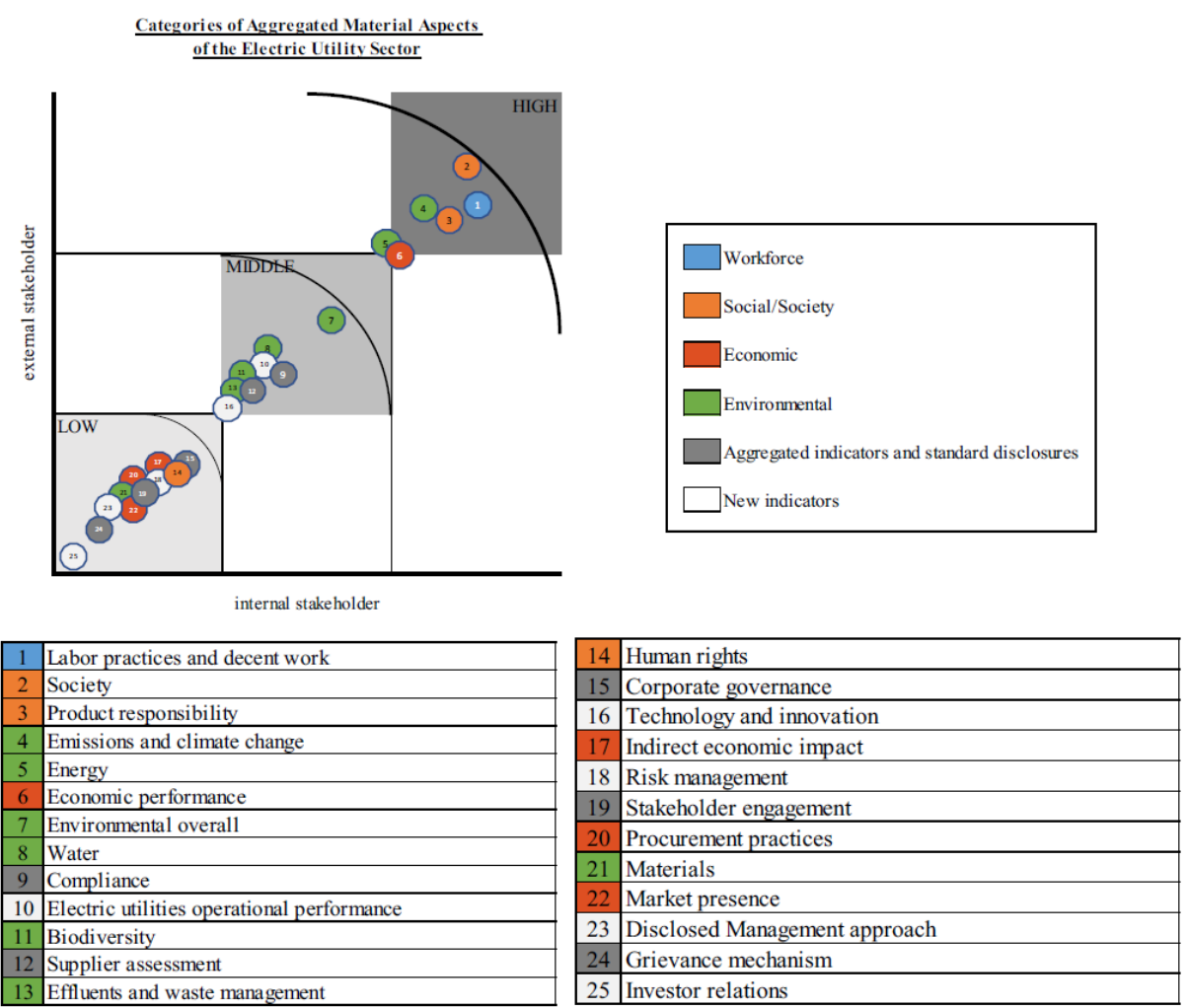

Fig. 3. Aggregated umbrella-materiality-matrix in SR by EUC [46].

Figure 3 shows an aggregated umbrella-materiality-matrix of internal and external stakeholders-material aspects and their relevance levels in the electricity sector. Regarding the social and environmental dimension, selective categories are highly relevant. Most categories of the environmental dimension show a medium relevance. The economic dimension has one highly relevant category.

In sum, materiality amounts to $48.1 \% \mathrm{TCR}$. The CR of the six highly relevant material categories shows only $54.4 \%$, far too low for highly relevant categories needing a required minimum CR of above $66.6 \%$. The TCR of only nine out of 22 material categories significantly correlate with the stakeholder relevance level. 13 material categories are not in compliance with stakeholders' information needs. Only two out of six highly relevant material categories show a significant correlation and compliance, i.e., 'economic performance' and 'emissions and climate change'. Results show that the CR of materiality is selective and insufficient. 


\subsection{Governing IL for implemented SMCS (RQ2)}

Interviews show that the economic dimension is guided by the business logic. The community logic mainly governs managerial attitudes for the social dimension. The compliance logic is more often found when addressing the ecological dimension. The compliance logic is not a dominant logic and relates more to the business logic than to the community logic (see Table 1). All three logics are not in competition but emerge as hybrid logics regarding SD in Austrian EUC.

Table 1. Matrix of TBL-dimensions and IL frequencies [47].

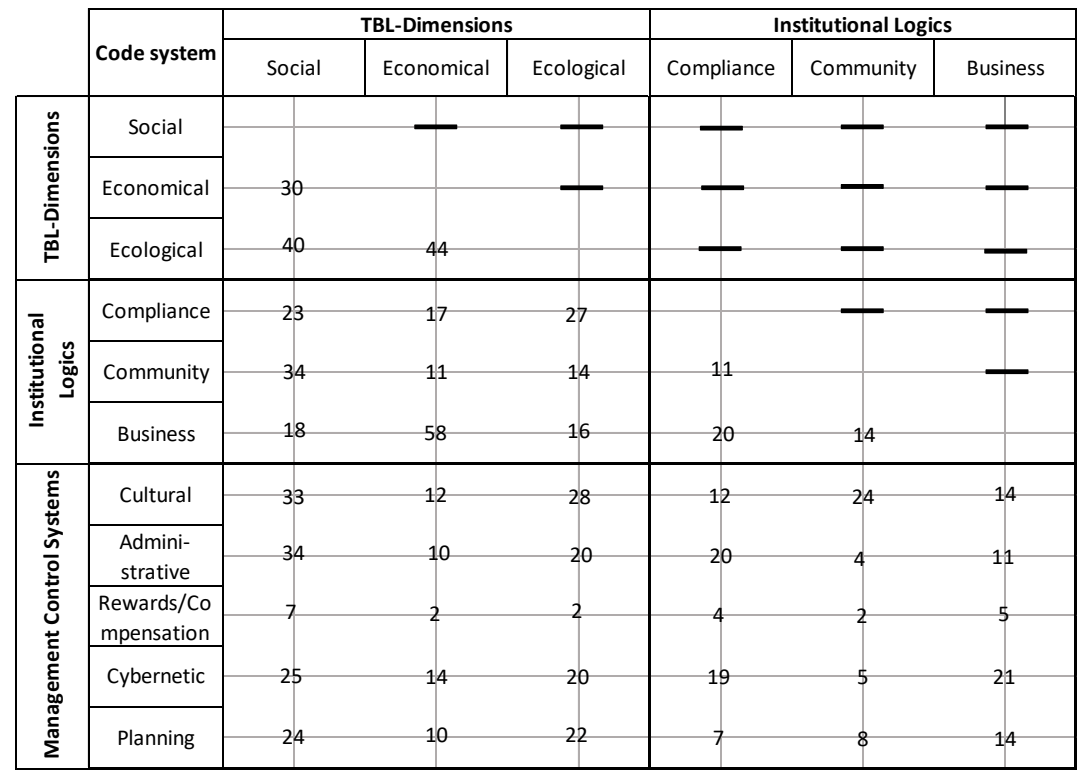

Findings show, that administrative controls are the most applied controls for sustainability agendas in combination with cultural controls and planning controls. To a lesser degree, also cybernetic controls exist. However, this is only due to one interview partner that explained mostly traditionally applied operative MCS which are explicitly not connected to sustainability objectives and control mechanisms as stated: "I belief the people (employees) are overwhelmed. [...] If people are questioned, nobody thinks of sustainability. But if you question them only in regard to goals, then you will hear sustainability goals. [...] Because employees do not have to know that these are sustainability goals. [...] They know the goals and do not know that these are sustainability goals. Furthermore, the analysis shows that mainly formal controls in combination with administrative controls are used for sustainability agendas. SMCS are thus selectively implemented and applied. Moreover, selective strategic SMCS on the top-management level lead to classic standardized MCS on the operative level. However, when evaluating SMCS, an iceberg-effect was noticed. While top-management articulates sustainability strategies and management controls, the operative level is not aware of sustainability agendas and objectives and continues to use classic MCS. This results in a decoupling from the sustainability agendas (see Figure 4).

Sustainability managers have a crucial position when implementing SMCS. Part of their duties is regarded to bridging strategic sustainability agendas on the top-management-level to the operative level by creating awareness. 


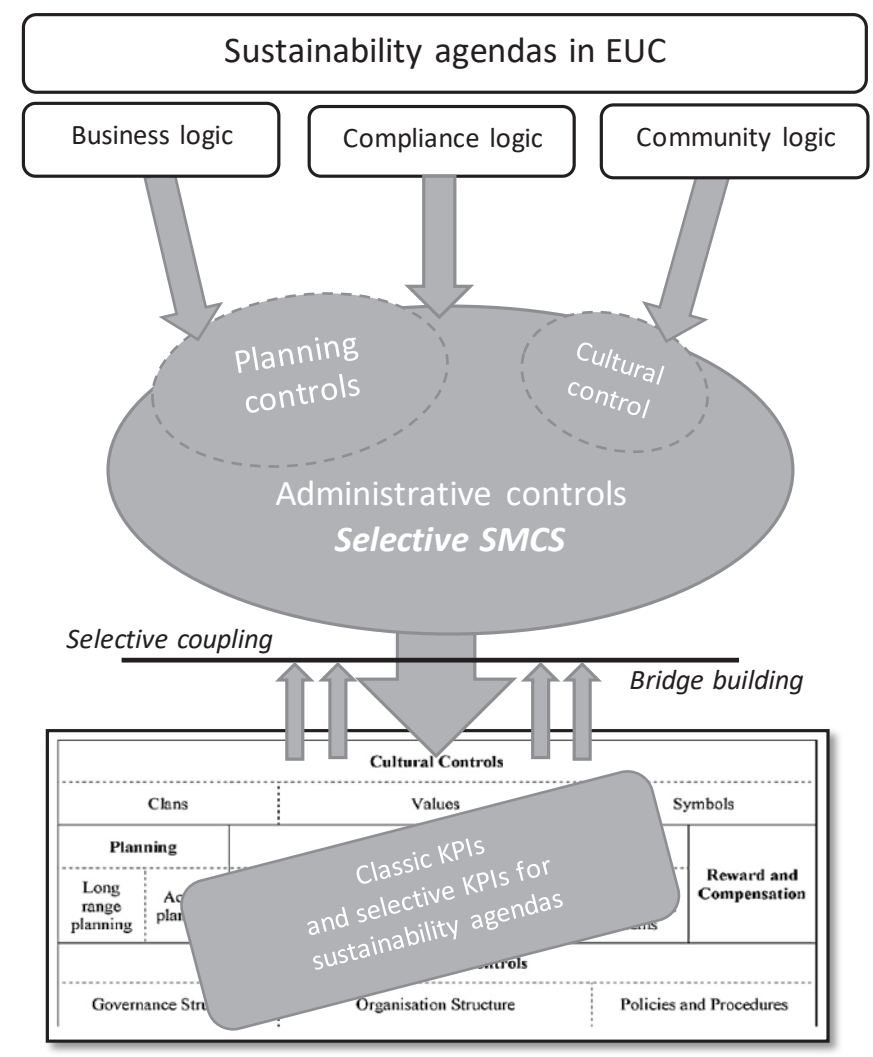

Fig. 4. Selective SMCS governed by IL [based on 47].

\section{Discussion, contribution and practical implications}

Despite the global impact of EUC on worldwide climate change issues, the sector is still under-researched regarding their SR and SMCS.

A sector-wide identified selective coupling regarding sustainability agendas of EUC, e.g., the partly insufficient and selective coverage in SR and the reactive and selective use of SMCS, that can be rendered as superficial conformity $[48,13]$ or even as maneuver of impression management [49]. EUC consistently and sector-wide focus on selective sustainability issues. The findings concerning materiality (answering RQ1) revealed an only partial or selective coupling. This can be interpreted as 'cherry picking' or reporting only what EUC want to report. In light of institutional theory and unlike expected, isomorphic forces lead to a sector-wide selective homogenization and selective coupling regarding the practice of SD.

EUC do not sufficiently comply with suggested principles by standard setters, like the GRI, showing a lack of compliance to stakeholders' accountability. SR as communicationtool is not sufficiently stakeholder-oriented. The mediocre and selective documentation of management approaches regarding sustainability agendas goes along with the lack of defined sustainability KPIs. However, this jeopardizes the image and credibility of EUC even further. Hence, the term impression management for a way to create an idealized image [50] seems justified. EUC should consider that the lack of stakeholder compliance reduces the extent of stakeholder value creation in the sector. 
Furthermore (answering RQ2), selective SMCS remain on the strategic top-management level in the electricity sector and are mainly used to set sustainability agendas, create a chain of responsibility, plan future sustainability targets and innovations. So far, EUC still face the difficulty of defining sustainability KPIs necessary for cybernetic and reward controls as required for a holistic 'SMCS as a package'. The selective coupling from the sustainability agendas in EUC is a sign of a limited and reactive position of integrating SD and implementing SMCS which is consequently noticed in their selective disclosure in SR. For that, [41] suggests a holistic integration of SD emphasizing on a new business model for sustainability agendas.

Moreover, a further insight and contribution of this study is having identified that hybrid logics govern the managerial focus on sustainability issues. The logics complement each other. The restrictive and selective use of SMCS in EUC could however be interpreted as early-stage development of hybrid logics in the electricity sector, based on [41].

Although, coping strategies of EUC are in use and help sustainability managers to adjust, integrate SD and implement SMCS. EUC would benefit from integrating the mediating role for bridge building exemplarily performed by bridging actors, in particular sustainability managers, who create awareness through communication and sense making, matching the suggestions by [15]. Hybrid logics ought to govern managerial coping strategies for a successful and holistic implementation of SMCS. Hence, EUC may continue to show a selective coupling from the sustainability agendas whilst hybrid logics are still at an early stage $[30,41]$. Moreover, the selective stakeholder compliance and the reactive integration of SD coupled with selectively implemented SMCS have the potential of adverse effects on the reputation of EUC. This could lead to even closer scrutiny and even tighter sector regulations. EUC miss the opportunity to gain stakeholder trust, creating stakeholder value by complying with stakeholder information needs. Based on findings, it can be assumed that the continuous privatization of the sector is globally beneficial to stakeholders and their attribution of organizational and public value.

In sum and as practical implications, governments and regulators should increase their coercive pressure in essential areas monitoring the sustainability performance and management approaches for SD in EUC eventually leading to homogenization in the sector. This could also help assuring the focus on material aspect and compliance. Standard-setters could use the identified set of sector-specific material aspects of high and middle relevance and urge EUC to focus on these aspects. This would cut the seemingly arbitrary selection of material aspect, leaving less room to pick and choose indicators and more room for detailing and focussing on sector-specific materiality.

Furthermore, since $E U C$ are in a highly climate sensitive sector with growing scrutiny by critical stakeholders, EUC would be well advised to disclose materiality transparently and focus their SM-approaches at least on all highly relevant material aspects. This would help gaining back trust of critical stakeholders. Moreover, EUC can improve their SD by focusing on a holistic implementation of SMCS, including the definition of sustainability KPIs. Some $E U C$ establish a corporate responsibility department to formalize such bridging processes and to find reasonable KPIs for organizational SD. In that sense, EUC could improve their SD by creating sustainability awareness on the operative level and reset their existing governing logics to hybrid logics for implementing a holistic set of SMCS.

Finally, [41] emphasized on having to switch into a new managerial mode, away from a green-washing or impression management attempt and towards sustainability-value-creation being able to meet stakeholder needs. EUC should focus on a holistic approach of SD to comply with stakeholder demands. Conclusively, this paper suggests a managerial discourse framing new business models for sustainability to facilitate emerging hybrid logics for a holistic SD. 
Despite the significant empirical and theoretical insights in the electricity sector, limitations of this study are the exclusive focus on the sector and on GRI-G4 reports, the narrow coding perspective for the content analyses and the limited interviews. The actual sustainability performance of EUC was not analyzed offering avenues for further research. Future research could investigate specific business models for the sector for a successful holistic SD.

\section{References}

1. O. Boiral, I. Heras-Saizarbitoria, M.C. Brotherton, JBE, 1-19 (2019)

2. S. Sartori, S. Witjesb, L.M.S. Campos, Energ. Pol., 111, 41-51 (2017)

3. S. Garcia, Y. Cintra, R. d. C.S. Torres, F.G. Lima, JCP, 136, 181-196 (2016)

4. B. Fernandez-Feijoo, S. Romero, S. Ruiz, JBE, 122, 1 (2014)

5. A. A. Traxler, D. Greiling, Balt. J. Mgmt, online (2018). Access mode: https://doi.org/10.1108/BJM-10-2017-0337, 29.11.2018

6. N. A. S. Bahari, B. Alrazi, N. M. Husin, Proc. Eco. \& Fin., 35, 16 (2016)

7. C. Deegan, in J. Bebbington, J. Unerman, B.O’Dwyer (ed.), Sustainability Accounting and Accountability (2014)

8. CDP, Charged or static (2017)

9. J. A. Moseñe et al, JCP, 40, 199-211 (2013)

10. K. Bakhtina, J. W. Goudriaan, Trf.: Europ. Rev. of Lab. \& Res., 17, 1 (2011)

11. I. Lock, P. Seele, JCP, 122, 186-200 (2016)

12. D. Talbot, O. Boiral, JBE, 132, 2 (2015)

13. C. H. Cho, M. Laine, R. W. Roberts, M. Rodrigue, AOS, 40, 78-94 (2015)

14. M.d.M. Miras-Rodríguez, A. Carrasco-Gallego, B. Escobar-Pérez, BSE., 24, 8 (2015)

15. R. Lueg, R. Radlach, EMJ, 34, 2 (2016)

16. A. Ditillo, I. E. Lisi, JMAR, 28, 2 (2016)

17. J. Bebbington, I. Thomson, MAR, 4, 24 (2013)

18. R. L. Burritt, S. Schaltegger, AAAJ, 23, 7 (2010)

19. T. Ahrens, C. Chapman, AOS, 32, 1 (2007)

20. K. Langfield-Smith, AOS, 22, 2 (1997)

21. C. Villiers, P. Rouse, J. Kerr, JCP, 136, 78-85 (2016)

22. E. G. Hansen, S. Schaltegger, Cent. f. Sust. Mngm. (Working Paper Series, 2012)

23. E. Guenther, J. Endrikat, T. W. Guenther, JCP, 136, 147-171 (2016)

24. J. P. Gond, S. Grubnic, C. Herzig, J. Moon, MAR, 23, 3 (2012)

25. C. Herriau, L. Touchais, JCM, 15, 1 (2015)

26. C.A. Adams, AAAJ, 17, 5 (2004)

27. R. Greenwood, M. Raynard, F. Kodeih, E.R. Micelotta, M. Lounsbury, AMA, 5, 1 (2011)

28. P. J. DiMaggio, W. W. Powell, in W. W. Powell, P. J DiMaggio (ed.), The new Institutionalism in Organizational Analysis (1991)

29. J. W. Meyer, B. Rowan, Am. J. of Soc., 83, 2 (1977)

30. A. C. Pache, F. Santos, AMJ, 56, 4 (2013) 
31. M. I. Herremans, A. J. Nazari, JMAR, 28, 2 (2016)

32. T. Malmi, D. Brown, MAR, 19, 4 (2008)

33. M. Bradford, J. B. Earp, D. S. Showalter, P.F. Williams, Acc. Hor., 31, 1 (2016)

34. S. Benn, D. Dunphy, A. Griffiths, Organizational change for corporate sustainability (2014)

35. C. Lebelhuber, D. Greiling, Rev. Mang. Sc., 1-43 (2021)

36. B. Comyns, F. Figge, AAAJ, 28, 3 (2015)

37. P. H. Thornton, W. Ocasio, M. Lounsbury, The Institutional Logics Perspective, (2012)

38. M. Lounsbury, AMJ, 50, 2 (2007)

39. P. H. Thornton, W. Ocasio, Am. J. of Soc., 105, 3 (1999)

40. M. Boitier, A. Rivière, Comp.-Contr.-Aud., 22, 3 (2016)

41. D. Argento, F. Culasso, E. Truant, Util. Pol., 40, 125-133 (2016)

42. J. G. York, T. J. Hargrave, D.F. Pacheco, AMJ, 59, 2 (2016)

43. C. Oliver, AMR, 16, 1 (1991)

44. M. B. Miles, A. M. Huberman, J. Saldana, Qualitative Data Analysis (2013)

45. R. K. Yin, Case study research, (2013)

46. J. Slacik, D. Greiling, JPBAFM, 32, 3 (2020)

47. J. Slacik, D. Greiling, J. Eng. Sec. Mgmt., 14, 3 (2019)

48. J. Slacik, D. Greiling, J. Eng. Sec. Mgmt. (in publication) DOI: 10.1108/IJESM-062020-0016

49. K. M. Shabana, A.K. Buchholtz, A.B. Carroll, B\&S, 56, 8 (2017)

50. E. Boxenbaum, S. Jonsson, in R. Greenwood, et al, (ed.), The SAGE Handbook of Organizational Institutionalism (2008)

51. J. Puroila, J. Kujala, H. Mäkelä, AMP, 1, 12697 (2016)

52. S. Alexius, G. Grossi, G., J. Manag. Gov., 22, 285-313 (2018) 


\section{Appendix 1}

\begin{tabular}{|c|c|c|c|c|c|c|c|c|}
\hline \multicolumn{7}{|c|}{ Overview Austrian EUC } & \multicolumn{2}{|l|}{ Revenue in EUR } \\
\hline \multicolumn{7}{|c|}{ OMVAG* } & & 23461 \\
\hline \multicolumn{7}{|c|}{ Verbund $\mathrm{AG}^{*}$} & & 3895,02 \\
\hline \multicolumn{7}{|c|}{ Gazprom Neft Trading GmbH } & & 2371 \\
\hline \multicolumn{7}{|c|}{ EnergieAllianz Austria GmbH (EAA)* } & & 2298 \\
\hline \multicolumn{7}{|c|}{ EVN AG* } & & 2204 \\
\hline \multicolumn{7}{|c|}{ Energie AGOberösterreich* } & & 1813,40 \\
\hline \multicolumn{7}{|c|}{ Wien Energie GmbH } & & 1677,36 \\
\hline \multicolumn{7}{|c|}{ Salzburg AG für Energie, Verkehr und Telekommunikation } & & 1536,14 \\
\hline \multicolumn{7}{|c|}{ Energie Steiermark $\mathrm{AG}^{*}$} & & 1373 \\
\hline \multicolumn{7}{|c|}{ Kelag - Kärntner Elektrizitäts-AG* } & & 1300,11 \\
\hline \multicolumn{7}{|c|}{ Tiwag - Tiroler Wasserkraft $\mathrm{AG}^{*}$} & & 1286,18 \\
\hline \multicolumn{7}{|c|}{ BP Europa SE Zweigniederlassung BP Austria* } & & 1141 \\
\hline \multicolumn{7}{|c|}{ Shell Austria GmbH } & & 1104,41 \\
\hline \multicolumn{7}{|c|}{ OeMAGAbwicklungsstelle für Ökostrom AG } & & 1058,07 \\
\hline \multicolumn{7}{|c|}{ Doppler Mineralöle GmbH* } & & 1025,29 \\
\hline \multicolumn{7}{|c|}{ Eni Austria GmbH (vormals Agip Austria GmbH) } & & 912,03 \\
\hline \multicolumn{7}{|c|}{ Linz AG für Energie, Telekommunikation, Verkehr und Kommunale Dienste* } & & 829,8 \\
\hline \multicolumn{7}{|c|}{ MOL Austria Handels GmbH } & & 750,5 \\
\hline \multicolumn{7}{|c|}{ Energie Direct Mineralölhandels GmbH (vormals: Shell Direct Austria GmbH) } & & 667,93 \\
\hline \multicolumn{7}{|c|}{ Vorarlberger Illwerke AG(illwerke vkw)* } & & 667,9 \\
\hline \multicolumn{9}{|c|}{ Case Study Sample Descrition } \\
\hline $\begin{array}{l}\text { EUC } \\
\text { Code }\end{array}$ & $\begin{array}{c}\text { Austrian } \\
\text { Region }\end{array}$ & Listed & Ownership** & Employees & $\begin{array}{c}\text { Revenue in } \\
\text { EUR }\end{array}$ & $\begin{array}{c}\text { Market } \\
\text { share }\end{array}$ & $\begin{array}{c}\text { Interview partner (IP) } \\
\text { Position/department }\end{array}$ & $\begin{array}{c}\text { IP } \\
\text { Code }\end{array}$ \\
\hline $\mathbf{A}$ & 1 & yes & 100\% Public & 2200 & 1.44 Billion & $9 \%$ & $\begin{array}{l}\text { Corporate innovation and } \\
\text { sustainability manager }\end{array}$ & 1 \\
\hline B & 2 & yes & $100 \%$ Public & 1200 & 600 Mio & $4 \%$ & Sustainability manager & 2 \\
\hline $\mathbf{C}$ & 3 & yes & $75 \%$ Public & 1700 & 1.27 Billion & $8 \%$ & $\begin{array}{l}\text { Manager of the department } \\
\text { of energy strategy and } \\
\text { efficiency }\end{array}$ & 3 \\
\hline D & 4 & yes & $86 \%$ Public & 1500 & 1.28 Billion & $8 \%$ & $\begin{array}{l}\text { Environmental and energy } \\
\text { manager }\end{array}$ & 4 \\
\hline $\mathbf{E}$ & 5 & yes & 90\% Public & 900 & 370 Mio & $2 \%$ & Sustainability manager & 5 \\
\hline \multirow{4}{*}{$\mathbf{F}$} & \multirow{4}{*}{6} & \multirow{4}{*}{ yes } & \multirow{4}{*}{ 76\% Public } & & & & $\begin{array}{l}\text { Corporate communication } \\
\text { manager }\end{array}$ & 6 \\
\hline & & & & 4500 & 1.63 Billion & $11 \%$ & CEO & 7 \\
\hline & & & & 4500 & 1.05 Dimoni & 1170 & $\begin{array}{l}\text { Technical manager/QM***_ } \\
\text { manager }\end{array}$ & 8 \\
\hline & & & & & & & Personal manager & 9 \\
\hline & & & & & & & Sustainability manager & 10 \\
\hline $\mathbf{G}$ & 7 & yes & $85 \%$ Public & 2700 & 2.85 Billion & $19 \%$ & Sustainability expert & 11 \\
\hline & & & & & & & Internal auditor/ $\mathrm{QM}$ *** & 12 \\
\hline
\end{tabular}

Largest energy utilities in Austria by net sales in 2019 (in million euros)

* Consolidated sales. All companies that generated the majority of their net sales in the energy supply sector were taken into account.

Source: Statistik Austria, 2020

** All Austrian public electric utilities are also interrelated with each other owning shares

*** QM: qualitiy management 


\section{Appendix 2}

\begin{tabular}{|c|c|c|}
\hline \multicolumn{3}{|c|}{ Codification Guideline } \\
\hline \multicolumn{3}{|c|}{ TBL-Dimensions based Elkington (1997) and GRI-Standard 2016} \\
\hline \multirow{3}{*}{$\begin{array}{c}\text { TBL- } \\
\text { Dimensions }\end{array}$} & Economical & $\begin{array}{l}\text { E.g., financial business targets, investments, profits, } \\
\text { rentability, liquidity, efficiency }\end{array}$ \\
\hline & Ecological & $\begin{array}{l}\text { E.g., environmental targets, innovation and technology, } \\
\text { energy production, reduction of pollution and waste, focus } \\
\text { on biodiversity, water, reduced use of enivronmental } \\
\text { resources }\end{array}$ \\
\hline & Social & $\begin{array}{l}\text { E.g., employement targets, percentage of women at work/in } \\
\text { leadership, data protection, community issues, supplier and } \\
\text { customer issues, access to energy, energy outages, } \\
\text { education and training, apprentisships, }\end{array}$ \\
\hline \multicolumn{3}{|c|}{ MCS as package' based on Malmi and Brown (2008) and Lueg and Radlach (2016) } \\
\hline \multirow{5}{*}{ SMCS } & Cultural Controls & $\begin{array}{l}\text { E.g., vision, mission, beliefs, values, norms, code of } \\
\text { conduct, clan and team spirit, symbols and organizational } \\
\text { identity }\end{array}$ \\
\hline & Planning Controls & $\begin{array}{l}\text { E.g., strategic approaches, budgets and forecasts, planned } \\
\text { actions and behavior, future approaches and } \\
\text { implementations }\end{array}$ \\
\hline & Cybernetic Controls & $\begin{array}{l}\text { E.g., financial and non-financial KPIs, measurements, } \\
\text { performance measurements, all (TBL) indicatoirs }\end{array}$ \\
\hline & $\begin{array}{c}\text { Reward and } \\
\text { Compensation }\end{array}$ & $\begin{array}{l}\text { E.g., bonuses and monetary incentives, promotions, pay } \\
\text { increase, social incentives }\end{array}$ \\
\hline & Administrative Controls & $\begin{array}{l}\text { E.g., corporate governance, organizational sturcture, } \\
\text { hierachical levels of authority, policies and procedures, } \\
\text { delegations and regulations }\end{array}$ \\
\hline \multicolumn{3}{|c|}{ Public EUC logics based on Argento et al. (2016) } \\
\hline \multirow{3}{*}{$\begin{array}{l}\text { Institutional } \\
\text { Logics }\end{array}$} & Business Logic & $\begin{array}{l}\text { E.g., having to run a business, being profitable, financial } \\
\text { and economical values, effectiveness and efficiency - seek } \\
\text { opportunities for growth, cost cutting, partnerships }\end{array}$ \\
\hline & community Logic & E.g., satisfying stakeholders and community demands \\
\hline & compliance Logic & $\begin{array}{l}\text { E.g., having to comply to regulations, rules and } \\
\text { requirements, governance settings, contractual opportunities } \\
\text { and boundaries, stakeholder demands }\end{array}$ \\
\hline \multirow[t]{2}{*}{$\begin{array}{l}\text { New Possible } \\
\text { Logics }\end{array}$} & sustainability Logic & $\begin{array}{l}\text { Stewardship attitude or action to serve society addressing all } \\
\text { TBL-aspects, (e.g., green thinking, ecologically efficiency, } \\
\text { local foot-print, diversity and gender, technology and } \\
\text { innovation, employment and training, ...) }\end{array}$ \\
\hline & hybrid Logics & $\begin{array}{l}\text { Logic that combines business and/or community and/or } \\
\text { compliance logics }\end{array}$ \\
\hline
\end{tabular}

